\title{
Manual de los Reglamentos del Agua en Florida: Sistemas de Tanques de Almacenamiento de Contaminantes ${ }^{1}$
}

Michael T. Olexa, Luke D'Isernia, Laura Minton, Dulcy Miller y Sara Corbett ${ }^{2}$

\section{Prefacio}

Este manual esta diseñado para proporcionar un resúmen autorizado, exacto y actual de las principales leyes Federales y de Florida que están directa o indirectamente relacionadas a la agricultura. Este manual debe proveer una vista general de los muchos derechos y responsabilidades que tienen los agricultores y propietarios de tierras agrícolas bajo las leyes tanto Federal como de Florida, así como también la información de los contactos apropiados para obtenerla con más detalle. Sin embargo, el lector debe estar advertido de que algunas partes de esta publicación podrían volverse obsoletas en cualquier momento, debido a que las leyes, reglas administrativas, y decisiones de la corte, sobre las cuales se basa este manual, se encuentran bajo revisión constante. Algunos detalles de las leyes citadas no se mencionan, debido a limitaciones de espacio.
Este manual es distribuido con la aclaración de que los autores no intentan proporcionar una asesoría legal o profesional, y que la información contenida aquí no debe ser considerada como un sustituto de asesoría profesional. En este manual, no se incluye toda la información para llevar a cabo el cumplimiento de las leyes Federales y de Florida y los reglamentos que rigen la protección del agua. Por estas razones, el uso de estos materiales por cualquier persona, constituyen un acuerdo para mantener libre de perjuicios a los autores, al Servicio de Extensión Cooperativa de Florida, al Instituto de los Alimentos y Ciencias Agrícolas y a la Universidad de Florida por reclamos de responsabilidad, daños o gastos provenientes de quien sea, por haberse referido o basado en la información contenida en este manual.

1. Este es el documento EDIS FE096, una publicación de Food and Resource Economics Department, Florida Cooperative Extension Service, Institute of Food and Agricultural Sciences, University of Florida, Gainesville, FL. Publicado Noviembre 2006. Por favor visite la página electrónica de EDIS en http://edis.ifas.ufl.edu.

2. Michael T. Olexa, profesor, Food and Resource Economics Department y director, Agricultural Law Center, University of Florida, Gainesville, FL, y presidente, Agricultural Law Committee, The Florida Bar; Luke D'Isernia, alumni, Levin College of Law, University of Florida, Gainesville, FL; Laura Minton, abogado, Dean, Mead, Egerton, Bloodworth, Capouano y Bozarth, PA, Orlando FL; Dulcy Miller, abogado, Foley and Lardner, LLP, Orlando, FL; y Sarah Corbett, abogado, Florida Second District Court of Appeal, Lakeland, FL. La traducción del ingles al español estuvo a cargo de Filiberto Reyes-Villanueva.

EI Instituto de Alimentos y Ciencias Agrícolas es un empleador que opera bajo Acción Afirmativa y provee Oportunidades Igualitarias, autorizado a proveer investigación, información educativa y otros servicios, únicamente a los individuos e instituciones que operan sin discriminación alguna con relación al credo, color, religión, edad, incapacidad, sexo, orientación sexual, estado civil, nacionalidad, opinion política o afiliaciones. Para más información sobre como obtener otras publicaciones de extensión, comuníquese con la oficina de Servicio de Extensión de su condado. Servicio de Extensión de la Florida / Instituto de Alimentos y Ciencias Agrícolas / Universidad de la Florida / Larry Arrington, Decano. 


\section{¿Quién Regula los Sistemas de Tanques de Almacenamiento de Contaminantes?}

La reglamentación del estado de los tanques estacionarios de almacenamiento, es de dominio primario del Departamento de Protección Ambiental de Florida (DPA). Este Departamento tiene el poder de regular los tanques de almacenamiento de contaminantes a través de los Estatutos de Florida, particularmente del Capitulo 376, "Remoción y Prevención de las Descargas de Contaminantes". Consecuentemente, la mayoría de las reglas cubiertas en esta sección son aquellas del DPA. Es importante notar, sin embargo, que las regulaciones permiten a los gobiernos individuales del condado a promulgar sus propias reglamentaciones. Esos reglamentos locales pueden ser más exigentes que los del DPA. Las autoridades del condado deberán ser consultados aun si la actividad del tanque de almacenamiento o la condición del mismo esta aparentemente sin los estándares de todo el estado.

\section{¿Qué Es Un Contaminante?}

Un tanque caerá dentro del alcance de las regulaciones, si mantiene un contaminante. Un "contaminante" esta definido básicamente como sigue:

- Cualquier tipo de aceite en cualquier forma.

- Gasolina.

- Cualquier plaguicida.

- Cualquier compuesto o derivado de amonio o cloro, excluyendo el petróleo de gas liquido.

\section{¿Cuáles Sistemas Son Regulados?}

La mayor parte de las regulaciones solamente se aplican para los sistemas de tanques de almacenamiento, cuya capacidad de almacenamiento individual es mayor de 110 galones. Los tanques más pequeños solamente necesitan cumplir con los requerimientos generales de que ellos no descargan su contenido en el medio ambiente y que cumplen con los estándares de prevención del fuego.
Hay una lista de 23 tipos de sistemas de tanques de almacenamiento que están exentos de este capitulo. Cualquier sistema agrícola de tanque de almacenamiento de 550 galones o menor, esta exento. Para una lista actualizada de los sistemas de tanques de almacenamiento revise con el DPA.

El DPA hace importantes distinciones entre los tanques nuevos y aquellos que ya estaban en operación antes de 1992. Los tanques nuevos están sujetos a los mas estrictos estándares de seguridad, pero los tanques existentes deben cumplir con muchos de los mismos estándares, para protección de sobre llenado, sistemas de monitoreo y el revestimiento de los tanques en un periodo dado de tiempo. El tiempo permitido para este "retroajuste" varia dependiendo del año en que el tanque fue instalado, pero el DPA contempla el retroajuste completo de todos los tanques existentes para el 2009.

Los sistemas superficiales están sujetos a reglamentación menos estricta y están sometidos a este capitulo, si tienen una capacidad de almacenamiento mayor a 550 galones. (Un tanque "superficial" no tiene mas de 10 por ciento de su volumen enterrado, incluyendo su tubería integral). Esos tanques, sin embargo, están sometidos a registros similares, manteniendo reglas de los tanques enterrados, y deben estar equipados con una barrera impermeable para capturar los derrames. Además, cualquier parte del tanque en contacto con el suelo debe ser protegido contra la corrosión.

\section{¿Qué Deberían Hacer los Propietarios de los Sistemas?}

Aparte de los permisos federales, estatales y locales, exigidos para la construcción física e instalación de sistemas de tanques de almacenamiento, no hay requerimientos para permisos de parte directa del DPA o de la reglamentación local de tanques. Sin embargo, los dueños del sistema deben hacer lo siguiente:

- Registrar los tanques con el DPA, 30 días antes de comenzar la instalación.

- Notificar al DPA 30 días antes del cierre de cualquier sistema de tanque de almacenamiento o 10 días antes que ocurra un reemplazo o actualización del un sistema. 
- Notificar al DPA en los 30 días de cambio de propietario de un sistema de tanque de almacenamiento.

- Reportar de inmediato cualquier derrame que represente cualquier amenaza a la calidad del medio ambiente (esto incluye, descargas que excedan 100 galones en las superficies permeables).

\section{¿Cuáles Son los Estándares Papra Pruebas, Construcción y Reparación?}

Todos los tanques nuevos deben cumplir con una amplia lista de requerimientos de seguridad, incluyendo doble -pared o construcción reforzada, sistemas de monitoreo (incluyendo monitoreo de pozos), placas antigolpes, sistemas eléctricos de aislamiento y otras especificaciones. Requerimientos similares han sido promulgados por los sistemas de tubería usados en conexión a los tanques y se exige protección contra la corrosión.

El DPA también estipula amplios requerimientos para probar la integridad de los tanques, y para la toma de muestras de los mismos, monitoreo de los pozos y suelo de las inmediaciones del tanque. Todas las pruebas deben llevarse a cabo por personal entrenado. Aunque los intervalos de pruebas son especificados en las reglas, el DPA retiene la autoridad para ordenar un sistema completo de pruebas, siempre que se estime necesario, basado en lo siguiente:

- Las fallas del operador para cumplir con las reglas.

- Evidencia de una descarga o de contaminación en el área.

Los operadores de las instalaciones de almacenamiento son requeridos para mantener registros de inspección del DPA. Esos registros deben incluir los resultados de todas las inspecciones y pruebas así como el mantenimiento de las notas de inventario sobre los tanques o sus contenidos. Los registros deben remontarse al menos a dos años y deben estar disponibles al DPA dentro de los cinco días de realizada la noticia.

\section{¿Cuáles Son los Procedimientos y Protecciones de la Limpieza?}

Los operadores deben ser obligados por la ley federal y estatal, para adoptar un Control de Prevención de Derrame y un Plan de Contramedida antes de la instalación de un tanque. Esto, es según la política federal de monitorear a cualquiera con el potencial de contaminar el medio ambiente a través de las descargas de petróleo. Este plan, o un plan alternativo aprobado por el DPA, deberán detallar el drenaje y otras medidas de ingeniería tomadas para mitigar el daño de derrames, y pueden requerir, un compromiso escrito de avance de los materiales y mano de obra que será usado para la limpieza de cualquier derrame que pueda ocurrir.

Como se anotó anteriormente, los derrames deben ser reportados inmediatamente, y el propietario u operador deben tomar inmediatamente los pasos para "contener, remover o debilitar la descarga". Si la calidad del agua subterránea esta amenazada por el derrame, el DPA también puede ordenar al propietario tomar cualquier acción correctiva que sea necesaria para reducir el peligro para el público.

\section{¿Cuál Es el Procedimiento Apropiado Para el Tanque Abandonado?}

El apropiado procedimiento para el tanque abandonado es como sigue:

- Los tanques abandonados deben ser bombeados y limpiados de vapor meticulosamente.

- Los tanques subterráneos deben ser removidos del suelo, o deben ser rellenados con arena, concreto, o un material inerte similar:

- Los tanques dispuestos como basura deben ser perforados o hacerlos inservibles.

- Los tanques de petróleo que están previstos para re-usarlos deben ser claramente etiquetados como "no uso para alimento".

- El tanque no abandonado debe ser usado paran almacenar contaminantes. Los tanques abandonados no deben ser re-usados a no ser que 
sean completamente actualizados para cumplir

con los estándares de tanques nuevos.

Conforme con la Ley de Responsabilidad, Compensación y Respuesta Ambiental Segura (LRCRAC), los propietarios deben mantener la responsabilidad por la fuga de los tanques que han sido abandonados en su propiedad por propietarios anteriores. Consecuentemente, los compradores deberán inspeccionar meticulosamente la propiedad antes de comprarla (ver FE584, LRCRAC), Si la fuga de los tanques son descubiertas, la limpieza debe ser supervisada por el propietario o por la APA. Esto será inevitablemente costoso.

\section{Fuente}

Capítulos 376, de los Estatutos de Florida, Secciones 376.30 al 376.326; Titulo 62, del Código Administrativo de Florida; Código 40 de las Reglamentaciones Federales, Secciones 280 y 281

\section{Información de Contacto}

Manejo de Sistemas de Tanques de Almacenamiento de Contaminantes (FE099, Agencias de Contacto)

- S-2 Departamento de Protección Ambiental de Florida

- L-4 Rama de Emergencia del Superfondo

- F-3 Ley Del Plan de Emergencia Comunitaria al Derecho- de-Saber

- F-4 LCST Servicio de Información de Asistencia

\section{Agradecimientos}

Los autores agradecen al personal de las agencias estatales y federales por su tiempo y asesoría en la preparación de este manual. Los autores agradecen especialmente a Richard Budell del Office of Agricultural Water Policy of the Florida Department of Agriculture and Consumer Services por el apoyo económico para el desarrollo de esta publicación. 